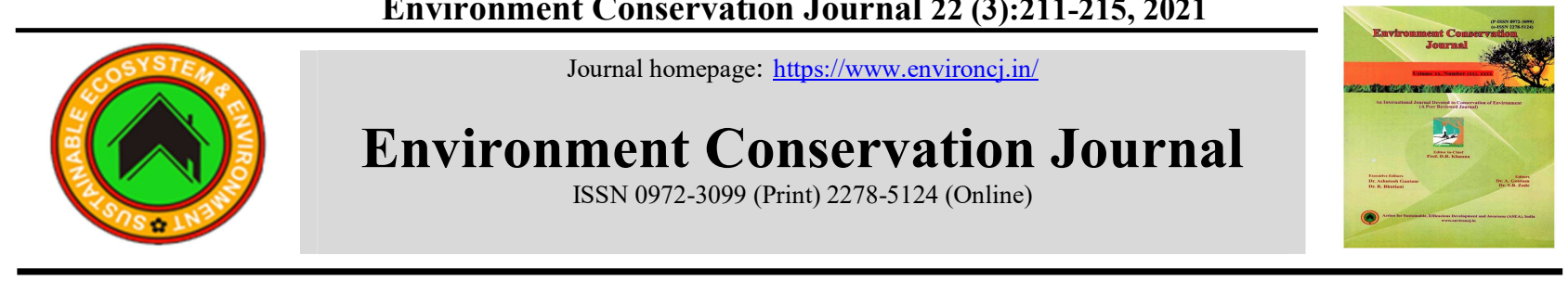

\title{
Antagonistic activity of rice rhizosphere isolates Xanthomonas oryzae pv. oryzae bacterial blight pathogen
}

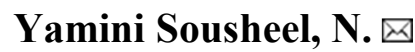

Department of Plant Pathology, College of Agriculture, PJTSAU, Hyderabad

Bharati Narayan Bhat

Department of Plant Pathology, College of Agriculture, PJTSAU, Hyderabad

Gouri Shankar Laha

Department of Plant protection, Indian Institute of Rice Research, Rajendranagar, Hyderabad

Triveni, $\mathbf{S}$

Division of Environmental Soil Science, ICAR-IISS, Bhopal (Madhya Pradesh), India

\begin{tabular}{|c|c|}
\hline ARTICLE INFO & ABSTRACT \\
\hline $\begin{array}{l}\text { Received : } 01 \text { June } 2021 \\
\text { Revised : } 06 \text { October } 2021 \\
\text { Accepted : } 10 \text { October } 2021 \\
\text { Available online: } 9 \text { December } 2021 \\
\text { Key Words: } \\
\text { Antagonism } \\
\text { Inhibition } \\
\text { Rhizosphere }\end{array}$ & $\begin{array}{l}\text { Attempts were made to isolate beneficial bio agents from rice rhizosphere } \\
\text { which resulted in isolation of } 46 \text { Bacillus spp and } 15 \text { fluorescent Pseudomonas } \\
\text { spp which were further investigated for their potential aginst BB of rice } \\
\text { diseaseAmong twenty six isolates of Bacillus, two isolates were most } \\
\text { antagonistic and showed highest inhibition percentage (57.09) The potential } \\
\text { isolates of Pseudomonas (P-4, P-5, P-6, P-7 and P-8), Bacillus (ARI 1-2, ARI } 2 \text { - } \\
4 \text {, ARI 1-3, D1-1-2 and D2-1-1) were tested in vivo under glass house conditions } \\
\text { for antagonism against Xoo which revealed that P-7 was effective in reduction } \\
\text { of lesion length (18.5cm) when compared to control (20.37cm). The potential } \\
\text { isolates of Pseudomonas (P-4, P-5, P-6, P-7 and P-8), Bacillus (ARI 1-2, ARI } 2 \text { - } \\
4 \text {, ARI 1-3, D1-1-2 and D2-1-1) were tested in vivo under glass house conditions } \\
\text { for antagonism against Xoo which revealed that P-7 was effective in reduction } \\
\text { of lesion length (18.5cm) when compared to control (20.37cm). The present } \\
\text { study indicated that PGPR isolates P-4, P-6, P-7 and P-8 can be used as } \\
\text { biofertilizers, which will add up for enhanced growth of rice. }\end{array}$ \\
\hline
\end{tabular}

\section{Introduction}

Rice (Oryza sativa L.) is the most important staple food for the ever increasing Indian population and is the world's leading food crop. It is cultivated over an area of about $158 \mathrm{M}$ ha with a production of about $725 \mathrm{Mt}$ in the world (FAO, 2016-17). It occupies second place next to wheat in terms of area and production. Among the rice growing countries, India has the largest area (46.8 Mha) followed by China and Indonesia. In India, rice is grown in almost all the states with a production of 105.4 Mt (FAO, 2019-20). In the state of Telangana, it is predominantly grown in an area of 20 lakh ha with a production of 66.2 lakh tonnes (INDIASTAT,2019-20).Rice varieties like BPT 5204, MTU 1010, JGL 1798 and Tella hamsa are widely grown in Telangana and are very popular among the farmers because of their high yield, desirable grain and cooking quality. Despite their popularity, they are susceptible to many pest and diseases like blast, bacterial blight, sheath blight, brown spot, tungro virus and others. Bacterial blight $(\mathrm{BB})$ is a major production constraint in India especially in irrigated and rain fed lowland ecosystem. The disease appeared in epidemic form in north western India during 1979 and 1980, in Pallakad region of Kerala during 1998 and several parts of Andhra Pradesh during 2010 and 2013. Bacterial blight caused by Xanthomonas oryzae pv. oryzae ((Ishiyama) Swings) has become a serious constraint for rice production especially after introducing high yielding rice varieties. Crop loss assessment studies revealed that this disease reduces grain yield to varying levels, depending on the stage of the crop when the disease appears,

Corresponding author E-mail: nysousheel1308@gmail.com

Doi: https://doi.org/10.36953/ECJ.2021.22325

This work is licensed under Attribution-Non Commercial 4.0 International (CC BY-NC 4.0)

(C) ASEA 
climatic conditions, season and extent of nitrogen fertilizers. In India, the extent of yield losses can be as high as $50 \%$ during severe infection

In view of the economic importance of the crop and unsatisfactory control of the disease, considerable attention has been given on the development of resistant varieties for the management of disease. Emphasis is also being given on the alternative approaches for managing the disease including use of biological control and management of BB using botanicals. Hence the present study is planned with emphasis on biological control using antagonistic organisms isolated from rhizosphere soil.

\section{Material and Methods Isolation from rhizosphere soil}

Two grams of soil sample was weighed and suspended in twenty milli litre of distilled water and vortexed. For spore forming bacteria flasks were kept in water bath at $100-105^{\circ} \mathrm{C}$, unlike non spore forming bacteria, spread plate technique was followed for isolation, later pin sized colonies were picked up and cultures were purified on Potato Dextrose Yeast King's B mediaplates, later Bacillus sps were identified by staining and Pseudomonas fluorescens by fluorescein extraction test.

\section{Screening of isolates against $\mathrm{Xoo}$}

Bacillus isolates were screened in vitro for their antagonistic activity against $X o o$, it was carried out by streaking Xoo on to Modified Wakimoto's Agar plates and then on the three corners of the plate, three isolates of the Bacillus were spotted. Based on the inhibited growth of the Xoo in vicinity of the spotted isolate they were further evaluated.

Evaluation of the isolates by double layer technique

After screening the effective isolates were again evaluated using double layer technique in which the isolates i.e., Bacillus, Pseudomonas were cultured on PDY, PAM plates respectively by just spotting the bacteria onto the plates for 2 days. After incubation the plates were taken to Laminar chamber and placed in an upside down manner, then $1 \mathrm{ml}$ of chloroform is added into the lid of and left for evaporation, the vapours from the chloroform in the lid kills the Bacillus or Pseudomonas isolate in the plate. After this young culture of Xoo suspension is added to MWA soft agar, added onto the plates having the isolate culture and were incubated in up straight manner for 2-3 days, after incubation inhibition zone of the each isolate is to be observed and recorded, inoculated plates were incubated at $25 \pm 2^{0} \mathrm{C}$ for 5 days and per cent inhibition was calculated.

\section{Siderophore production assay}

The siderophore production was qualitatively assessed by Chrome Azurol S agar plate method (Schwyn and Neiland 1987). CAS agar plate method is well known as the universal test for detection of siderophores. Chrome azurol S solution was prepared and added to melted King's B Agar medium in the ratio 1:15 (1 part CAS solution and 15 parts King's B). Spot inoculation at the centre of the CAS plate was done from the actively growing cultures of Pseudomonas isolates. Colonies exhibiting an orange halo after 3 days incubation $\left(28 \pm 2^{0} \mathrm{C}\right)$ were considered positive for siderophore production and the diameter of the orange halo was recorded.

\section{Screening of antagonistic bacteria for PGP} activity in glass house

All the effective isolates i.e., both Bacillus and Pseudomonas were tested for PGP activity, by testing the effect of isolates on root and shoot growth can be tested. For this experiment five isolates of Bacillus and five isolates of Pseudomonas were taken which were most antagonistic in in vitro conditions were used for seed treatment. These treated seeds were sown in pots containing sterilized soil. Observations were recorded up to 15 days. Root length, shoot length and fresh weight of plants were also recorded.

\section{Results and Discussion}

Results from the spotting experiment revealed that out of 45 isolates of Bacillus, 22 isolates were found antagonistic against Xoo by producing typical inhibition zone with diameter ranging from $0.02-1.37 \mathrm{~cm}$, whereas, the other isolates were not capable to give significant inhibition zone and were not considered potentially antagonistic against Xoo. Promising antagonistic isolates were evaluated using double layer technique in which 22 isolates of Bacillus spp. and 15 isolates of fluorescent Pseudomonas spp. have shown inhibitory effect on Xoo. The inhibition zone against Xoo produced by different selected isolates Bacillus spp. ranged from $1.68 \mathrm{~cm}$ (in isolate ARI 1-4) to $6.8 \mathrm{~cm}$ (D-1-2-2) (Figure 1\&4). The growth inhibition (\%) among different isolates of Bacillus spp. ranged from 
Table 1: Antagonistic activity of Bacillus isolates against Xanthomonas oryzae pv. oryzae under in vitro conditions using double layer method of testing

\begin{tabular}{|c|c|c|c|}
\hline $\mathbf{S N}$ & $\begin{array}{l}\text { Isolate } \\
\text { name }\end{array}$ & Inhibition zone & $\begin{array}{c}\text { Growth } \\
\text { inhibition }\end{array}$ \\
\hline 1. & ARI 1-2 & $* * 5.77 \pm 0.10$ & $\begin{array}{c}* 41.10^{b} \\
(39.85)\end{array}$ \\
\hline 2. & ARI 2-4 & $5.57 \pm 0.24$ & $\begin{array}{l}38.48^{b} \\
(38.27)\end{array}$ \\
\hline 3. & ARI 1-3 & $5.07 \pm 0.05$ & $\begin{array}{l}31.71^{\mathrm{c}} \\
(34.26)\end{array}$ \\
\hline 4. & D1-1-2 & $6.8 \pm 0.00$ & $\begin{array}{l}57.09^{a} \\
(49.07)\end{array}$ \\
\hline 5. & D2-1-1 & $5.60 \pm 0.17$ & $\begin{array}{l}38.83^{b} \\
(38.51)\end{array}$ \\
\hline 6. & P-4 & $4.6 \pm 0.25$ & $\begin{array}{l}26.38^{b} \\
(30.79)\end{array}$ \\
\hline 7. & $\mathrm{P}-5$ & $4.27 \pm 0.12$ & $\begin{array}{l}22.55^{b c} \\
(28.31)\end{array}$ \\
\hline 8. & $P-6$ & $4 \pm 0.05$ & $\begin{array}{l}22.55^{b c} \\
(28.31)\end{array}$ \\
\hline 9. & P-7 & $6.47 \pm 0.03$ & $\begin{array}{l}51.68^{a} \\
(45.94)\end{array}$ \\
\hline 10. & $\mathrm{P}-8$ & $6.77 \pm 0.32$ & $\begin{array}{l}56.96^{\mathrm{a}} \\
(49.04)\end{array}$ \\
\hline \multicolumn{3}{|c|}{$\mathrm{CD}(\mathrm{p}=0.05)$} & 1.29 \\
\hline \multicolumn{3}{|c|}{ SEm \pm} & 0.47 \\
\hline \multicolumn{3}{|c|}{$\mathrm{CV}$} & 4.69 \\
\hline
\end{tabular}

*Figures in parentheses indicate arc sine transformed values.

$* *$ Means of three replications; values after \pm are standard error values.

As per Duncan's grouping means with the same letter are not significantly different.

Table 2: In vivo evaluation of potential antagonistic isolates of Bacillus and Pseudomonas.

\begin{tabular}{|c|c|c|}
\hline SN & Isolate name & Inhibition zone \\
\hline 1 & ARI 1-2 & $* 20.37 \pm 0.19$ \\
\hline 2 & ARI 2-4 & $20.30 \pm 0.33$ \\
\hline 3 & ARI 1-3 & $20 \pm 0.67$ \\
\hline 4 & D1-1-2 & $19.67 \pm 0.27$ \\
\hline 5 & D2-1-1 & $19 \pm 0.82$ \\
\hline 6 & $\mathrm{P}-4$ & $19.5 \pm 0.71$ \\
\hline 7 & $\mathrm{P}-5$ & $19.87 \pm 0.11$ \\
\hline 8 & $P-6$ & $19.4 \pm 0.17$ \\
\hline 9 & P-7 & $18.5 \pm 0.62$ \\
\hline 10 & $\mathrm{P}-8$ & $19.67 \pm 0.17$ \\
\hline 11 & Control & $20.67 \pm 0.54$ \\
\hline & $\mathrm{CD}(\mathrm{p}=0.05)$ & 1.86 \\
\hline & $\mathrm{SEm} \pm$ & 0.59 \\
\hline
\end{tabular}

Table 3: Plant Growth Promoting activity of effective isolates under glass house conditions

S. Isolate Plant growth promoting activities

\begin{tabular}{|c|c|c|c|c|l|}
\cline { 3 - 6 } No & name & $\begin{array}{l}\text { Seed } \\
\text { Germination } \\
\text { (\%) }\end{array}$ & $\begin{array}{l}\text { Root } \\
\text { Length } \\
\text { (cm) }\end{array}$ & $\begin{array}{l}\text { Shoot length } \\
\text { (cm) }\end{array}$ & $\begin{array}{l}\text { Fresh } \\
\text { weight(gm) }\end{array}$ \\
\hline 1 & D2-1-1 & 87.3 & $* 7 \pm 0.47$ & $* 16.33 \pm 0.54$ & $* 0.16 \pm 0.01$ \\
\hline 2. & D1-2-2 & 84.3 & $6.83 \pm 0.14$ & $14 \pm 0.47$ & $0.12 \pm 0.01$ \\
\hline 3. & ARI 1-2 & 87.6 & $5.33 \pm 0.54$ & $11.33 \pm 0.72$ & $0.07 \pm 0.01$ \\
\hline 4. & ARI 1-3 & 90.6 & $5.5 \pm 0.24$ & $15.67 \pm 0.27$ & $0.14 \pm 0.01$ \\
\hline 5. & ARI 2-4 & 81.3 & $6 \pm 0.94$ & $15.83 \pm 0.49$ & $0.13 \pm 0.02$ \\
\hline 6. & P-4 & 87.3 & $9.17 \pm 0.49$ & $14.33 \pm 0.72$ & $0.11 \pm 0.01$ \\
\hline 7. & P-5 & 90.3 & $7.17 \pm 0.49$ & $13 \pm 0.82$ & $0.15 \pm 0.04$ \\
\hline 8. & P-6 & 91.0 & $9 \pm 1.25$ & $18.33 \pm 2.33$ & $0.10 \pm 0.01$ \\
\hline 9. & P-7 & 94.4 & $7.83 \pm 0.49$ & $17.67 \pm 1.52$ & $0.13 \pm 0.01$ \\
\hline 10 & P-8 & 97.6 & $5 \pm 0.47$ & $16.67 \pm 0.98$ & $0.12 \pm 0.00$ \\
\hline 11 & Control & 82.0 & $7.33 \pm 0.27$ & $17.67 \pm 0.27$ & $0.15 \pm 0.01$ \\
\hline \multicolumn{2}{|c|}{ LSD } & - & 1.49 & 4.65 & 0.36 \\
$(P=0.05)$ & & & & \\
\hline \multicolumn{2}{|c|}{ SEm \pm} & - & 0.74 & 1.24 & 0.01 \\
\hline
\end{tabular}

Table 4: Siderophore production assay

\begin{tabular}{|c|c|}
\hline Isolate name & Reaction \\
\hline P- 4 & +++ \\
\hline P- 5 & +++ \\
\hline P- 6 & ++ \\
\hline P- 7 & ++ \\
\hline P- 8 & +++ \\
\hline
\end{tabular}

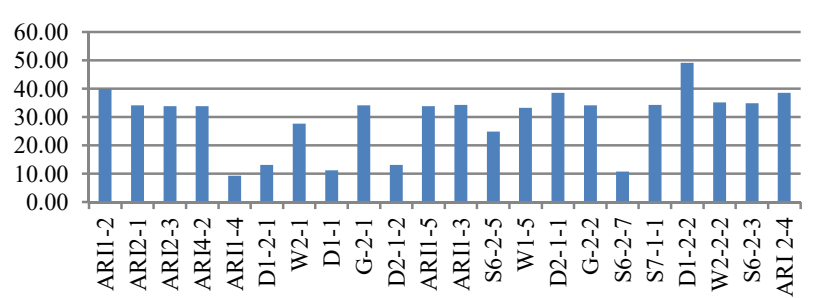

Figure 1: Graph showing the percent inhibition shown by different Bacillus isolates against $\mathrm{Xoo}$ in dual culture technique.

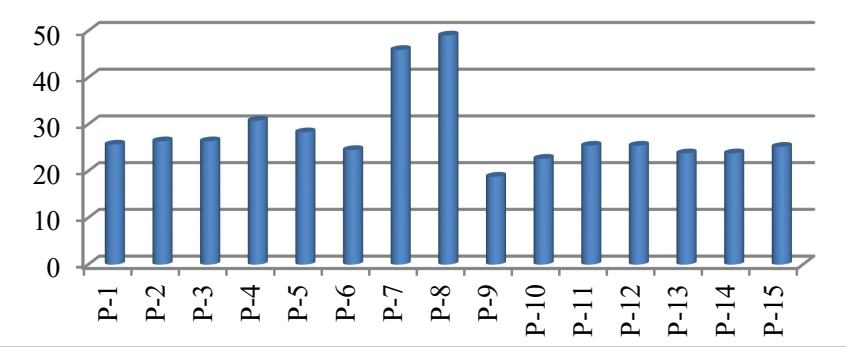

Figure 2: Graph showing the percent inhibition shown by different Pseudomonas isolates against $\mathrm{Xoo}$ in dual culture technique 


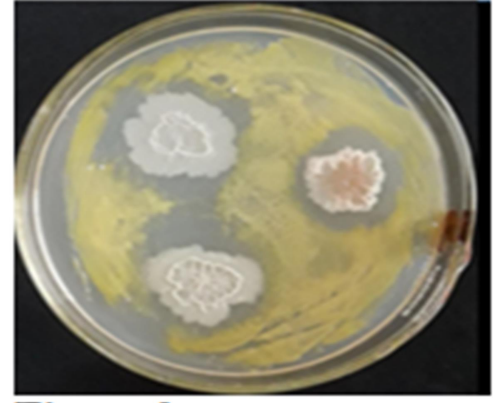

Figure 3

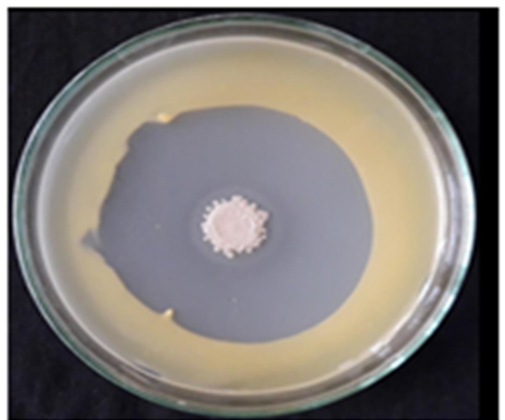

Figure 6

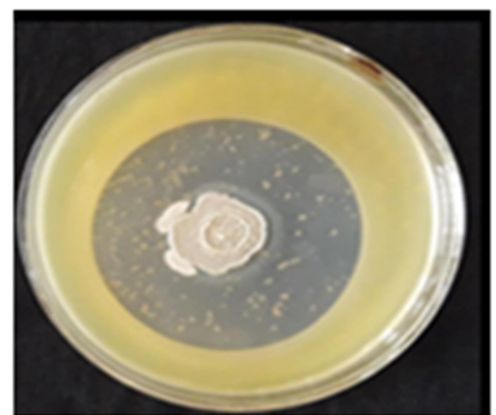

Figure 4

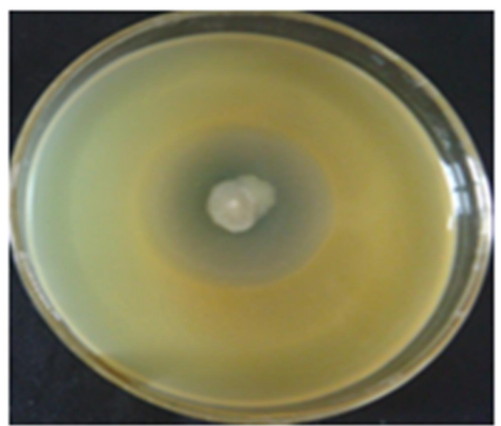

Figure 7

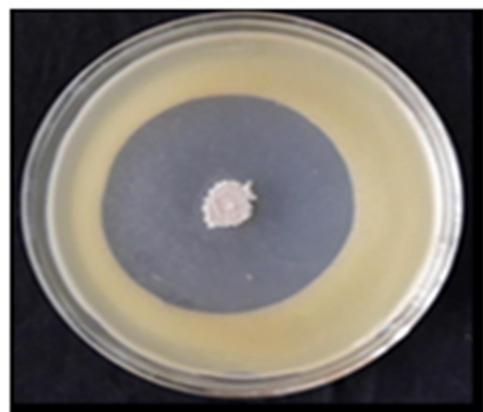

Figure 5

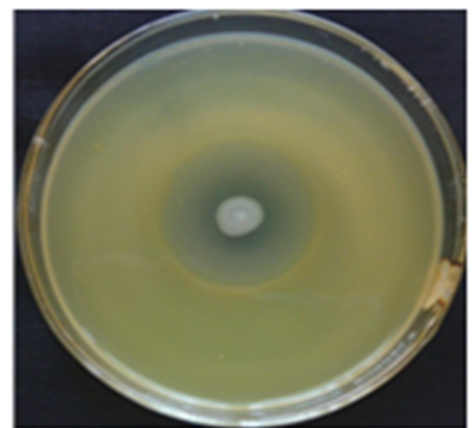

Figure 8

Figure 3: Screening of Bacillus isolates

Figure 4-6: Inhibition by Bacillus isolate in dual culture test

Figure 7\&8: Inhibition by Pseudomonas isolate in dual culture test

$2.56 \%$ (in case of ARI 1-4) to 57.09 (D1-2-2)(Table 1). Among 22 isolates of Bacillus spp., two isolates viz., D1-2-2, ARI 1-2 were highly antagonistic and showed highest growth inhibition percentage of $57.09 \%$ and $41.10 \%$ respectively. The inhibition zone produced against Xoo by different isolates of fluorescent Pseudomonas spp. ranged from $2.9 \mathrm{~cm}$ (in isolate P-9) to $6.77 \mathrm{~cm}$ (in isolate P-8) ( Fig.2\&5). The growth inhibition (\%) among different isolates of fluorescent Pseudomonas spp. ranged from $10.50 \%$ (in case of P-9) to 56.96 (in P8) (Fig.2). Among the 15 isolates of fluorescent Pseudomonas spp. Tested against Xoo, isolates P-8 exhibited 56.96 per cent growth inhibition followed by P-7 isolate (51.68 per cent) (Fig.2)(Table 2).

10 isolates of rhizosphere bacteria, which were effective during in vitro assay were chosen to investigate for their PGPR activity. Results confirmed that most of the isolates significantly enhanced different growth parameters like plant height, root length, and dry matter production of shoot and root of rice seedlings. The isolates notably enhanced the germination of rice seeds and this can be attributed to their capacity of siderophore production (Table 4). In case of Pseudomonas isolates

It is also noted that isolates enhanced the seed germination by 2.03 to $15.7 \%$ over the control. The highest seed germination was recorded when the seeds were pre treated with P-8 isolate. The isolates P-7, P-5, P-7 and D2-1-1 also showed superior performances to increase the seed germination. The PGPR isolates significantly increased the height of rice seedlings (Table 3 over untreated control. The highest plant height $(18.33 \mathrm{~cm})$ was recorded in seeds treated P-7 isolate. Even an increase in the root length was also observed and highest length of $9.13 \mathrm{~cm}$ was recorded plants pre-treated with P-4.

Several researchers reported antagonistic activity of different species of Bacillus against various plant pathogens including bacterial pathogens. These findings are in line with Saikia and Chowdhary (1993), who isolated the strains of Bacillus subtilis from rice plants which were highly antagonistic 


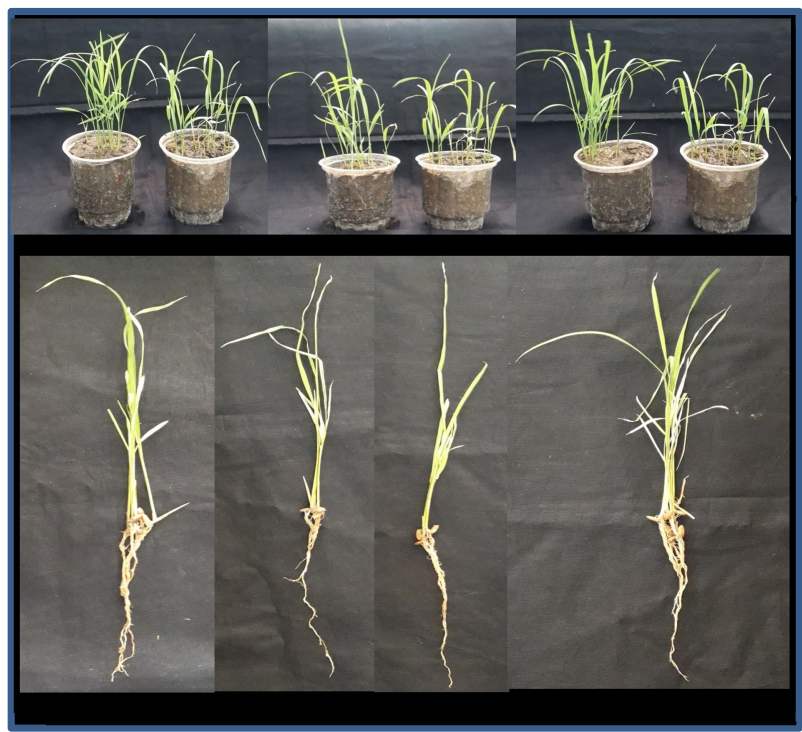

Figure 9: Glass house evaluation of PGP activity

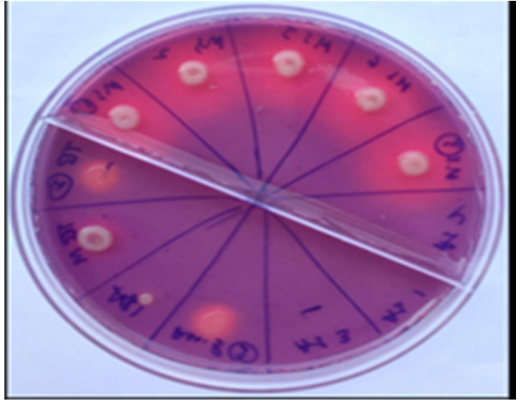

Figure 10: Siderophore assay

against Xoo and significantly reduced bacterial blight severity. Chauhan, (1973) also have reported that 30 isolates of B. Subtilis from rice inhibited the development of bacterial blight disease symptoms by 58.1 per cent. The antagonistic effect of $B$. subtilis and $P$. fluorescens against phytopathogenic

\section{References}

Dev, N., \& Dawande, A. Y. (2010). Biocontrol of soil borne plant pathogen Rhiozoctonia solani using Trichoderma spp. and Pseudomonas fluorescens. Asiatic Journal of Biotechnology Resources, 1, 39-44.

F.A.O. (2016-17). FAOSTAT Agriculture data (online). In: http://www.fao.org/and http://faostat.fao.org./. Rome, Italy : Food and Agriculture Organization (FAO).

Ganeshan, G., \& Manoj Kumar, A. (2005). Pseudomonas fluorescens, a potential bacterial antagonist to control plant diseases. Journal of Plant Interactions, 1(3), 123-134. fungi was attributed to the hydrolytic enzymes that can degrade cell walls, iron-chelating siderophores, and several cyclic lipodepsipeptides (Ganeshan and Kumar, 2007). Laha et al. (2009) also reported that strains of Pseudomonas fluorescens and Bacillus subtilis were highly inhibitory to the bacterial pathogen, Xoo at laboratory conditions.

Velusamy et al. (2006) documented that when $P$. fluorescens applied as foliar spray, it suppressed rice $\mathrm{BB}$ under field conditionand this can be attributed to $P$. fluorescens salicyclic acid and 2, 4diacetyl-phloroglucinol (2,4-DAPG) production. Dev and Dawande (2010) also evaluated the antagonistic property of $P$. fluorescens against Xanthomonas oryzae pv. oryzae which revealed that the peptolytic enzymes produced by these antagonists suppressed the growth of Xanthomonas oryzae by 70.9 per cent. These results are also in conformity with Wu et al. (2008) who investigated the ability of Bacillus subtilis in suppressing bacterial leaf blight and bacterial leaf streak of rice and reported that rice plants (cultivar 9311) treated with Bacillus subtilis A59 and Bacillus amyloliquefaciens exhibited a significant reduction in disease severity caused by Xanthomonas oryzae pv.oryzae relative to control. The inhibition caused by them were 58.82 to 72.31 per cent.

\section{Conclusion}

The present study concludes that out of 61 isolates collected 5 isolates from Bacillus sps. And 5 isolates of Pseudomonas were proven to effective under in vitro and glasshouse conditions and invites further exploitation by isolation of secondary metabolites and also encapsulation studies.

Laha, G.S., Virakthamath, B.C \& Priyanka (2009). Bacterial blight of rice and its management. Technical Bulletin No.4.Directorate of Rice Research (ICAR), Rajendranagar, Hyderabad-500 030, Andhra Pradesh, India.37 pp.

Saikia, P., \& Chowdhury, H. D. (1993). Phylloplane microflora for the control of bacterial leaf blight of rice caused by Xanthomonas oryzae pv. oryzae. Indian Phytopathology, 46, 218-218..

Wu, L., Goh, M. L., Sreekala, C., \& Yin, Z. (2008). XA27 depends on an amino-terminal signal-anchor-like sequence to localize to the apoplast for resistance to Xanthomonas oryzae pv oryzae. Plant Physiology, 148(3), 1497-1509. 